\title{
Two-Dimensional Modulation Technique with DC Voltage Control for Single-Phase Two-Cell Cascaded Converters
}

\author{
Jose I. Leon, Sergio Vazquez, Ramon Portillo, Leopoldo G. Franquelo and Eugenio Dominguez \\ Electronic Engineering Department \\ University of Seville \\ Seville, Spain 41092 \\ Email: jileon@gte.esi.us.es
}

\begin{abstract}
In this paper, a simple feed-forward modulation technique for single-phase two-cell multilevel cascaded converters is presented. All the possible switching states of the power converter are taken into account applying a two dimensional control region. The proposed technique uses the actual values of the DC-Link capacitor voltages to obtain output phase voltages and currents with low harmonic distortion with any dc voltage in the H-bridges of the cascaded converter. The possible switching sequences of the converter are studied and, depending on the actual dc voltage values, their desired values are achieved. Simulation results are shown in order validate the proposed technique working as a synchronous rectifier.
\end{abstract}

\section{INTRODUCTION}

A MONG the multilevel converter topologies, the cascaded H-bridge converter (CHB) is one of the most interesting topologies presenting high modularity, high quality harmonic spectra of output voltages and currents and high efficiency [1]-[4]. They have been used in medium and high power applications being a mature technology prepared to be used in industrial applications extensively [4], [5].

One of the most important topics related to $\mathrm{CHB}$ is the development of low cost and efficient modulation techniques. Several different modulation methods can be applied to CHB. Carrier-based PWM (level-shifted and especially phaseshifted), space vector modulation (SVM) and hybrid modulation are the most commonly used modulation techniques for multilevel converters [3]-[7]. Recently, several simple modulation techniques with very low computational cost have been presented [8]-[11].

This paper applies a time domain modulation for the singlephase two-cell cascaded converter (2C-CHB) shown in Fig. 1. The proposed modulation technique is named $2 \mathrm{D}$ feed-forward modulation (2DFFM). This modulation technique considers all the possible solutions to generate the desired phase voltage $V_{a b}^{*}$. The actual dc voltages of the power converter $\left(V_{C 1}\right.$ and $\left.V_{C 2}\right)$ are taken into account to determine the switching sequence and the switching times avoiding errors and achieving high quality output waveforms.

The controller implemented in this paper is based on two stages as is shown in Fig. 2. The external controller has to control the sum of the dc voltages of the $2 \mathrm{C}-\mathrm{CHB}$ and the internal controller is focused on the dc voltage control of each
H-bridge of the converter. The external one is a conventional controller where the error of the total dc-link voltage is used to determine the active power needed in the next sampling period. This active power is used to calculate the reference phase current which is controlled by a PI controller determining the reference phase voltage to be generated by the converter. It has to be noticed that in this work, a resonant filter to avoid the $100 \mathrm{~Hz}$ oscillations of the dc voltages is used to calculate the active power reference.

This paper is mainly focused on the introduction of the internal stage, highlighted in Fig. 2, where the reference phase voltage $V_{a b}^{*}$ is generated controlling the dc voltages of the Hbridges. The next sections are devoted to the introduction of the 2DFFM technique with dc voltage control.

\section{The Two-Dimensional FeED-Forward Control REGION OF THE 2C-CHB}

The control region of the $2 \mathrm{C}-\mathrm{CHB}$ can be represented in two dimensions (2D) using a plane where $x$ axis is the lower H-bridge output voltage $\left(V_{\text {lower }}\right)$ and $y$ axis is the upper $\mathrm{H}$ bridge output voltage $\left(V_{\text {upper }}\right)$ [12]. The 2D control region of the $2 \mathrm{C}-\mathrm{CHB}$ is represented in Fig. 3. This $2 \mathrm{D}$ control region is a feed-forward representation because the actual values of the dc voltages of the H-bridges $\left(V_{C 1}\right.$ and $\left.V_{C 2}\right)$ are used. In Fig. 3, as an example, it is assumed that $V_{C 1}>V_{C 2}$ showing that the $2 \mathrm{D}$ control region can be plotted with any condition of the dc voltage values of the CHB converter. Anyway, as a consequence of (2), it has to be fulfilled that

$$
V_{a b}^{*}=\delta_{\text {lower }}+\delta_{\text {upper }}
$$

The states of each H-bridge can be 0,1 or 2 where the $\mathrm{H}$ bridge $_{i}$ output voltage is $-V_{C i}, 0$ or $V_{C i}$ respectively. In Fig. 3 , each switching state of the $2 \mathrm{C}$-CHB is named $H_{u} H_{l}$ where $H_{u}$ and $H_{l}$ are the states of the upper and lower H-bridges respectively.

Each point of the $2 \mathrm{D}$ control region achieves a specific phase voltage $V_{a b}$. In the CHB, the phase voltage $V_{a b}$ is obtained as the addition of the output voltage of each H-bridge of the converter. Therefore, in the $2 \mathrm{C}-\mathrm{CHB}$ case, $V_{a b}$ is determined as the sum of $V_{\text {upper }}$ and $V_{\text {lower }}$, output voltages of upper and lower H-bridges respectively (see Fig. 1). 


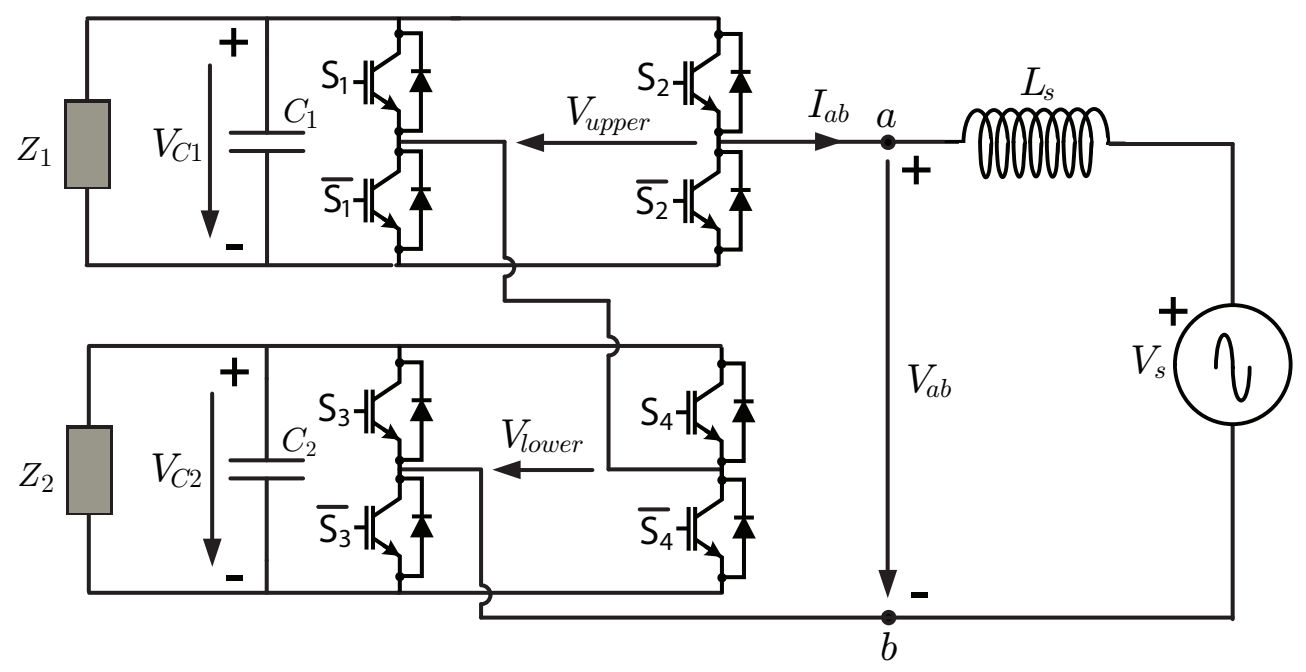

Fig. 1. Two-cell cascaded H-bridge converter working as a synchronous rectifier.

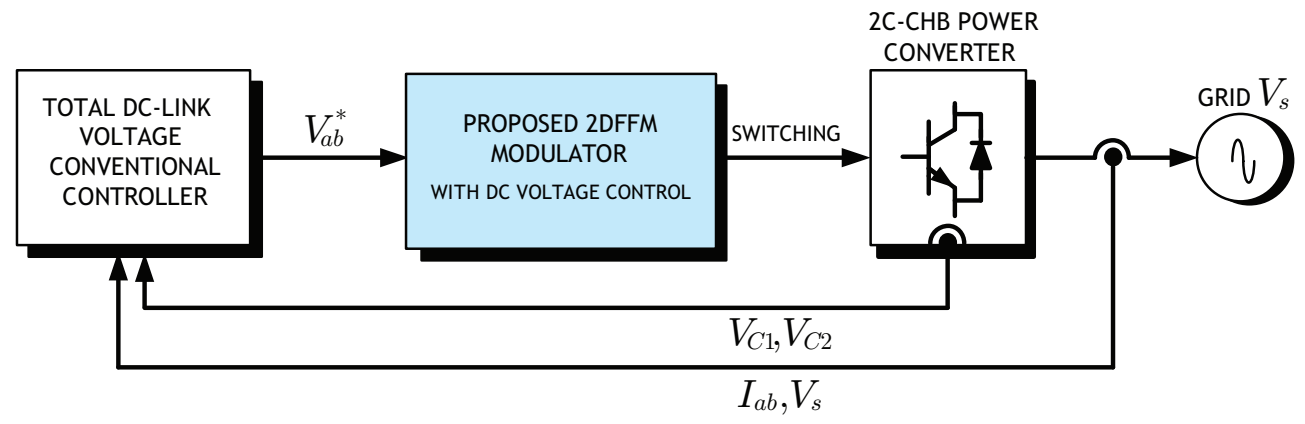

Fig. 2. Proposed control diagram. The 2DFFM technique achieves the control of the dc voltages of the 2C-CHB.

$$
V_{a b}=V_{\text {upper }}+V_{\text {lower }}
$$

It can be noticed that all the solutions to achieve one specific phase voltage form a diagonal line with $135^{\circ}$ slope because expression (2) has to be fulfilled [12].

\section{The Two-Dimensional FeED-Forward MODULATION TECHNIQUE FOR 2C-CHB}

As it is shown in Fig. 3, any point belonging to the solutions set can be used as the chosen point to achieve the desired phase voltage $V_{a b}^{*}$. Each possible solution can be defined using its $(x, y)$ components denoted as $\left(\delta_{\text {lower }}, \delta_{\text {upper }}\right)$.

The final point belonging to the solution set to achieve a specific output voltage $V_{a b}^{*}$ is determined by an external controller improving some design criterion. Considering that this point has been determined, $\delta_{\text {lower }}$ and $\delta_{\text {upper }}$ are the projections of the point over $x$ and $y$ axis respectively. The calculation of the switching sequence and the corresponding switching times is very simple and is summarized in Table I. The switching sequence is formed by two different switching states in each H-bridge. $H_{u i}$ and $H_{l i}$ are the states $i$ of the upper and lower H-bridges respectively $(i=1,2)$. The corresponding switching times are defined as $t_{u i}$ and $t_{l i}$ respectively. It can be noticed that the actual values of the dc voltages of the $\mathrm{H}$-bridges are used in the switching times calculation. This

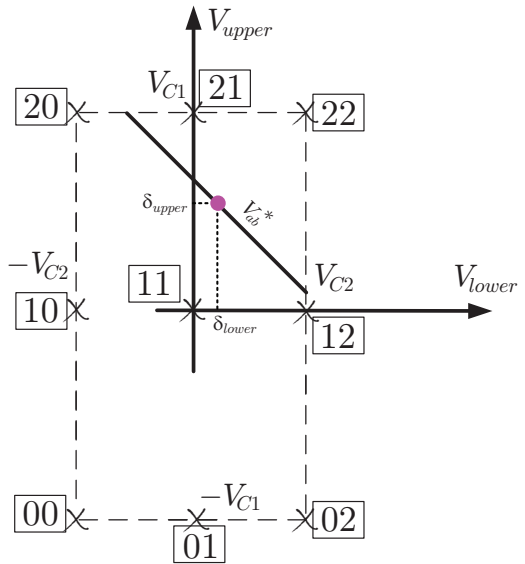

\section{$\mathrm{H}_{u} \mathrm{H}_{l}$ \\ $H_{u}$ : State of the upper $\mathrm{H}$-bridge $\mathrm{H}_{l}$ :State of the lower $\mathrm{H}$-bridge}

Fig. 3. 2D feed-forward control region of the 2C-CHB with $V_{C 1}>V_{C 2}$. The solution is defined using its $(x, y)$ components denoted as $\left(\delta_{\text {lower }}, \delta_{\text {upper }}\right)$

is a feed-forward compensation which has been previously used for the introduction of several modulation techniques applied to multilevel converters [13]-[16]. This feed-forward compensation avoids the low order distortion due to possible $\mathrm{dc}$ voltage imbalances in the converter. 
TABLE I

SWITCHING SEQUENCE AND SWITCHING Times CALCULATION OF THE PROPOSED 2DM TECHNIQUE

\begin{tabular}{c|c|c}
\hline \hline$\delta_{\text {lower }}$ & $\begin{array}{c}\text { Switching } \\
\text { Sequence }\end{array}$ & $\begin{array}{c}\text { Switching } \\
\text { Times }\end{array}$ \\
\hline$>0$ & $\begin{array}{c}H_{l 1}=1 \\
H_{l 2}=2\end{array}$ & $t_{l 1}=\frac{V_{C 2}-\left|\delta_{l o w e r}\right|}{V_{C 2}}$ \\
\hline$\leq 0$ & $\begin{array}{l}H_{l 1}=1 \\
H_{l 2}=0\end{array}$ & $t_{l 2}=\frac{\left|\delta_{l o w e r}\right|}{V_{C 2}}$ \\
\hline \hline$\delta_{u p p e r}$ & $\begin{array}{c}\text { Switching } \\
\text { Sequence }\end{array}$ & Switching \\
\hline$>0$ & $H_{u 1}=2$ & Times \\
\hline \multirow{2}{*}{$>0$} & $H_{u 2}=1$ & $t_{u 1}=\frac{\left|\delta_{u p p e r}\right|}{V_{C 1}}$ \\
& $H_{u 1}=0$ & $t_{u 2}=\frac{V_{C 1}-\left|\delta_{u p p e r}\right|}{V_{C 1}}$ \\
\hline \hline
\end{tabular}

Finally, it has to be noticed that a multiplicative effect in the switching frequency of the phase voltage $V_{a b}$ is obtained by using the 2 DFFM technique. In this way, the switching frequency of each H-bridge is the half of the switching frequency of the total output voltage. This is achieved by changing the order of the switching in the upper and lower cells as can be observed in Table I.

\section{2DFFM TECHNIQUE FOR 2C-CHB SYNCHRONOUS ReCtifiers ACHIEving DC Voltage Control}

In this paper, the control of the dc voltages of the $2 \mathrm{C}-\mathrm{CHB}$ has been applied as the criterion to calculate the best switching sequence of the 2DFFM technique. The derivation steps of the proposed controller are the following:

\section{A. Starting Point Calculation}

The developed control method has to choose one specific point from the solutions set as the starting solution. This initial solution point, named equilibrium point, is defined as $\left(E q_{x}, E q_{y}\right)$ as follows:

$$
\left(E q_{x}, E q_{y}\right)=\left(\frac{V_{a b}^{*}}{2}, \frac{V_{a b}^{*}}{2}\right) .
$$

The graphical representation of the equilibrium point is represented in Fig. 4. It can be noticed that this point is located on the $45^{\circ}$ slope line because of (3). This condition is usually fulfilled but, if the dc voltage unbalance is big enough, the equilibrium point could be out of the $2 \mathrm{D}$ control region becoming an impossible solution. In this case, the equilibrium point has to change to be on the solutions set. The necessary saturation of the equilibrium point is summarized in Table II.

\section{B. Definition of the Control Strategy}

All possible solutions obtained from the control strategy have to be on the solutions set fulfilling (1) and (2). Considering the synchronous rectifier application, the influence of changing the value of $\delta_{\text {lower }}$ and $\delta_{\text {upper }}$ on the dc voltages $V_{C 2}$ and $V_{C 1}$ respectively is studied. Depending on the phase

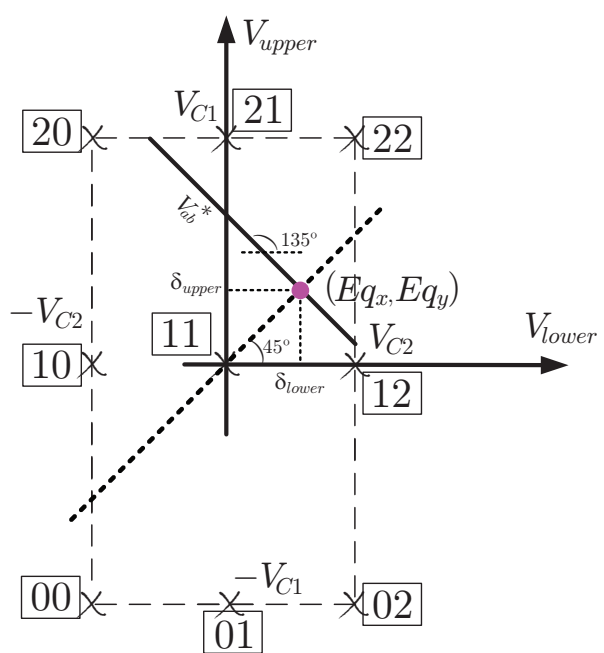

Fig. 4. Representation of the equilibrium point $\left(E q_{x}, E q_{y}\right)$ in the $2 \mathrm{D}$ control region of the $2 \mathrm{C}-\mathrm{CHB}$.

TABLE II

EQUILIBRIUM POINT SATURATION

\begin{tabular}{cc}
\hline \hline Condition & Equilibrium point $\left(E q_{x}, E q_{y}\right)$ \\
\hline$\frac{V_{a b}^{*}}{2}>V_{C 2}$ & $\left(V_{C 2}, V_{a b}^{*}-V_{C 2}\right)$ \\
$\frac{V_{a b}^{*}}{2}>V_{C 1}$ & $\left(V_{a b}^{*}-V_{C 1}, V_{C 1}\right)$ \\
$\frac{V_{a b}^{*}}{2}<-V_{C 2}$ & $\left(-V_{C 2}, V_{a b}^{*}+V_{C 2}\right)$ \\
$\frac{V_{a b}^{*}}{2}<-V_{C 1}$ & $\left(V_{a b}^{*}+V_{C 1},-V_{C 1}\right)$ \\
\hline \hline
\end{tabular}

TABLE III

INFLUENCE OF $\delta_{\text {lower }}$ AND $\delta_{\text {upper }}$ ON THE DC VOLTAGES

\begin{tabular}{ccc}
\hline \hline$\delta_{\text {lower }}$ & $\begin{array}{c}\text { Phase current } \\
\text { condition }\left(I_{a b}\right)\end{array}$ & $\begin{array}{c}\text { DC Voltage } \\
\text { Influence }\left(V_{C i}\right)\end{array}$ \\
\hline$\uparrow$ & $>0$ & $V_{C 2} \uparrow$ \\
$\downarrow$ & $>0$ & $V_{C 2} \downarrow$ \\
$\uparrow$ & $<0$ & $V_{C 2} \downarrow$ \\
$\downarrow$ & $<0$ & $V_{C 2} \uparrow$ \\
\hline \hline & & \\
\hline \hline$\delta_{\text {upper }}$ & Phase current & DC Voltage \\
& condition & Influence \\
\hline$\uparrow$ & $>0$ & $V_{C 1} \uparrow$ \\
$\downarrow$ & $>0$ & $V_{C 1} \downarrow$ \\
$\uparrow$ & $<0$ & $V_{C 1} \downarrow$ \\
$\downarrow$ & $<0$ & $V_{C 1} \uparrow$ \\
\hline \hline
\end{tabular}

current $I_{a b}$ sign (see Fig. 1), this influence can be determined and is summarized in Table III.

The controller used in this paper is a conventional PI controller applied to the calculation of $\delta_{\text {lower }}$ and $\delta_{\text {upper }}$. The mathematical expressions that form the PI controller have been designed taking into account the Table III. The controller design parameters $k_{p}$ and $k_{i}$ have to be positive real numbers. 


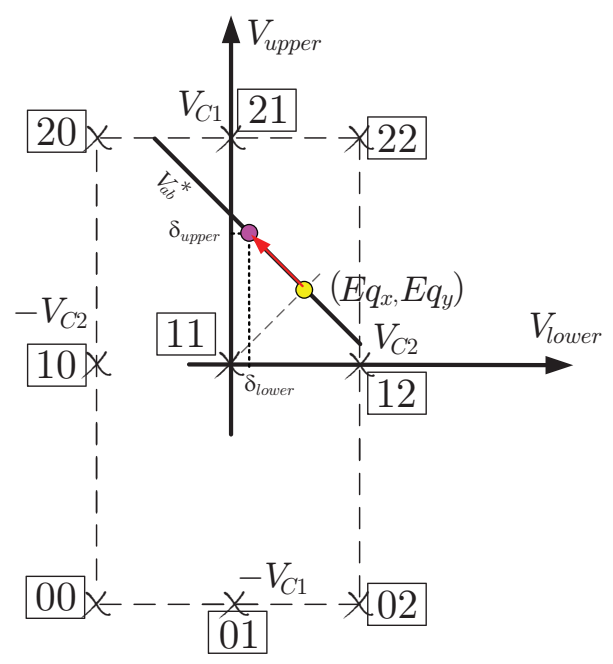

Fig. 5. Representation in the $2 \mathrm{D}$ control region of the $2 \mathrm{C}-\mathrm{CHB}$ of the chosen point $\left(\delta_{\text {lower }}, \delta_{\text {upper }}\right)$ starting from the initial solution $\left(E q_{x}, E q_{y}\right)$.

$$
\begin{gathered}
\Delta V_{C 1}=\left.\left(V_{C 1}^{*}-V_{C 1}\right)\right|_{t=t_{k}} \\
\Delta V_{C 2}=\left.\left(V_{C 2}^{*}-V_{C 2}\right)\right|_{t=t_{k}} \\
\xi_{k}=\left.\left(\Delta V_{C 1}-\Delta V_{C 2}\right) I_{a b}\right|_{t=t_{k}} \\
\chi_{k}=\frac{\xi_{k}+\xi_{k-1}}{2} \\
\delta_{\text {upper }}=\left.E q_{y}\right|_{t=t k}+k_{p} \xi_{k}+k_{i} \chi_{k} \\
\delta_{\text {lower }}=\left.V_{a b}^{*}\right|_{t=t_{k}}-\delta_{\text {upper }}
\end{gathered}
$$

The controller moves the selected point from the equilibrium point to a new one where $\delta_{\text {lower }}$ and $\delta_{\text {upper }}$ are chosen in order to achieve the control objective. This concept is graphically represented in Fig. 5. It is important to notice that using (4) any dc voltage can be applied to be controlled in the $2 \mathrm{C}-\mathrm{CHB}$ converter only changing the desired dc voltages $V_{C 1}^{*}$ and $V_{C 2}^{*}$. Using the 2DFFM technique and the dc voltage controller, any dc voltage can be achieved avoiding errors in the modulation if the dc voltages are not perfectly controlled (for instance in fast transients or without any load).

\section{Switching Sequence and Switching Times Calculation}

Once, $\delta_{\text {lower }}$ and $\delta_{\text {upper }}$ are determined by the controller using (4), the final switching states and the switching times can be easily calculated using Table I.

\section{Results of The 2DFFM TEChNiQue With DC VOLTAGE CONTROL FOR THE 2C-CHB}

The 2DFFM technique and the dc voltage controller have been tested using a $2 \mathrm{C}-\mathrm{CHB}$ connected to the grid $(230 \mathrm{~V}$, $50 \mathrm{~Hz}$ ) using an inductance $L_{s}$ equal to $2 \mathrm{mH}$. The switching frequency of each $\mathrm{H}$-bridge is equal to $2 \mathrm{kHz}$. A pure resistive load is connected to the dc side of the $2 \mathrm{C}-\mathrm{CHB}$ converter in order to test the behavior of the proposed technique.

In the first experiment, the two H-bridges of the $2 \mathrm{C}$ CHB have equal desired dc voltages $\left(V_{C 1}^{*}=V_{C 2}^{*}=200 \mathrm{~V}\right)$. The 2DFFM technique with the dc voltage control is successfully
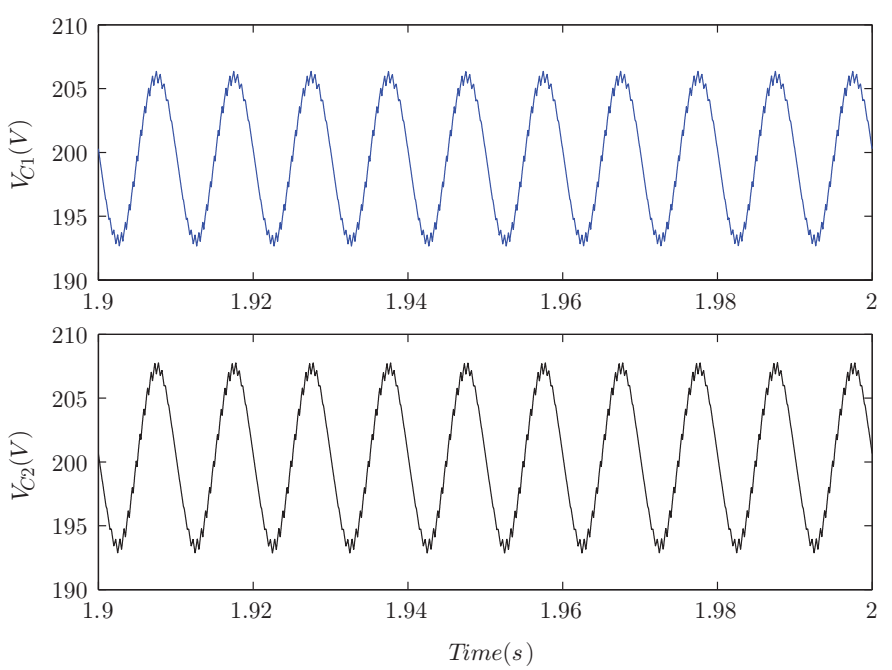

Fig. 6. Results of the 2DFFM technique achieving dc voltages balancing $\left(V_{C 1}^{*}=V_{C 2}^{*}=200 \mathrm{~V}\right)$. Instantaneous dc voltage of the H-bridges $\left(V_{C 1}\right.$ and $V_{C 2}$ ).

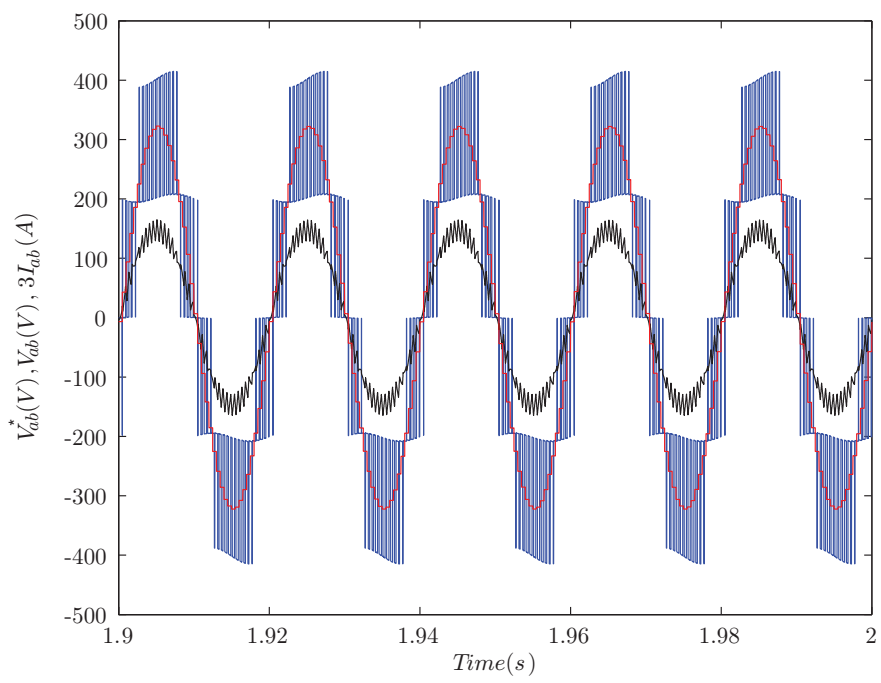

Fig. 7. Results of the 2DFFM technique achieving dc voltages balancing $\left(V_{C 1}^{*}=V_{C 2}^{*}=200 \mathrm{~V}\right)$. Phase current $I_{a b}$ multiplied by 3 , phase voltage $V_{a b}$ and phase voltage reference $V_{a b}^{*}$.

applied and the obtained instantaneous de voltages $V_{C 1}$ and $V_{C 2}$ are represented in Fig. 6 . The obtained phase current $I_{a b}$, the phase voltage $V_{a b}$ and its reference $V_{a b}^{*}$ are represented in Fig. 7. It can be observed that the desired dc voltage values of the $\mathrm{H}$-bridges are achieved whilst the unity power factor is obtained as well. A detail of the obtained phase voltage is depicted in Fig. 8 where the output voltage of each $\mathrm{H}$ bridge is represented. It can be noticed that the effective switching frequency of the phase voltage $V_{a b}$ is $4 \mathrm{kHz}$ due to the multiplicative effect obtained by the 2DFFM technique. Finally, the 2D control region and the chosen points by the controller are plotted in Fig. 9.

In a second experiment, the desired dc voltages of the two $\mathrm{H}$-bridges of the $2 \mathrm{C}$-CHB are suddenly changed from the balanced situation $V_{C 1}^{*}=V_{C 2}^{*}=200 \mathrm{~V}$ to have different desired dc voltages equal to $V_{C 1}^{*}=300 \mathrm{~V}$ and $V_{C 2}^{*}=100 \mathrm{~V}$. The transient response of the proposed controller is represented in Fig. 10. 

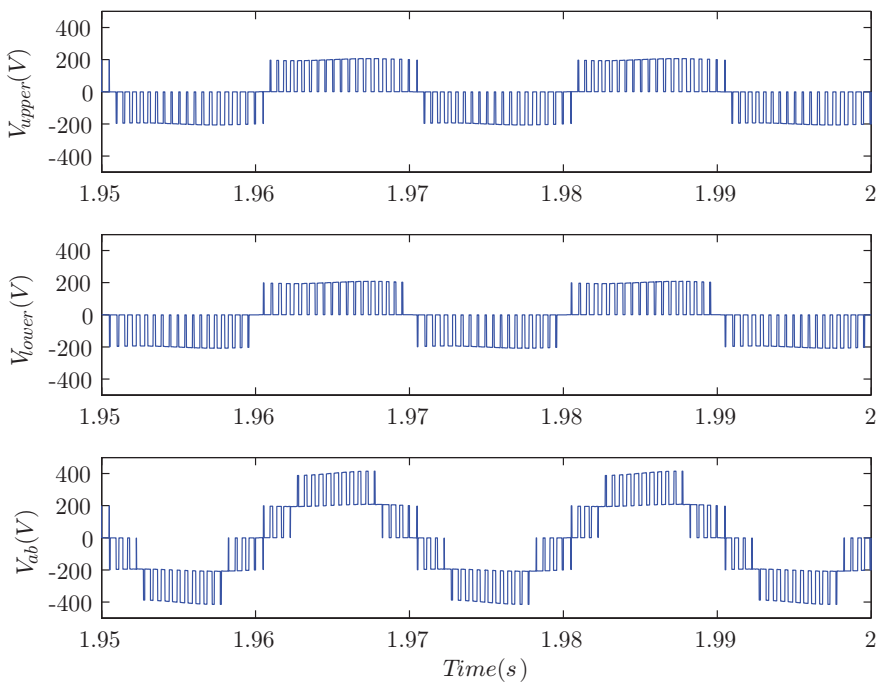

Fig. 8. Results of the 2DFFM technique achieving dc voltages balancing $\left(V_{C 1}^{*}=V_{C 2}^{*}=200 \mathrm{~V}\right)$. Output voltage of upper and lower H-bridges ( $V_{\text {upper }}$ and $\left.V_{\text {lower }}\right)$ and phase voltage $V_{a b}$.

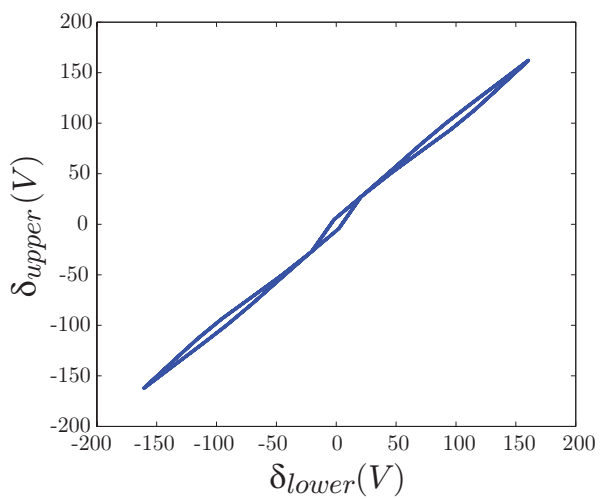

Fig. 9. Representation of the points used in the 2D control region in order to achieve dc voltages balancing $\left(V_{C 1}^{*}=V_{C 2}^{*}=200 \mathrm{~V}\right)$.

It can be observed that the new references are achieved in 40 miliseconds. In addition, as the number of levels increases due to the unbalanced dc conditions, the number of levels of the phase voltage increases as well.

In steady state conditions with $V_{C 1}^{*}=300 \mathrm{~V}$ and $V_{C 2}^{*}=100$ $\mathrm{V}$, the obtained instantaneous de voltages $V_{C 1}$ and $V_{C 2}$ are represented in Fig. 11. The obtained phase current $I_{a b}$, the phase voltage $V_{a b}$ and its reference $V_{a b}^{*}$ are represented in Fig. 12. As happens with the balanced case, tt can be observed that the desired dc voltage values of the H-bridges are achieved whilst the unity power factor is obtained as well. A detail of the obtained phase voltage in this unbalanced case is depicted in Fig. 13 where the output voltage of each H-bridge is represented. Finally, the 2D control region and the chosen points by the controller are plotted in Fig. 14.

\section{CONCLUSIONS}

In this paper, a simple two-dimensional modulation technique for single-phase two-cell multilevel cascaded converters has been used to achieve a useful target such as the dc voltage control in a rectifier application. The proposed controller
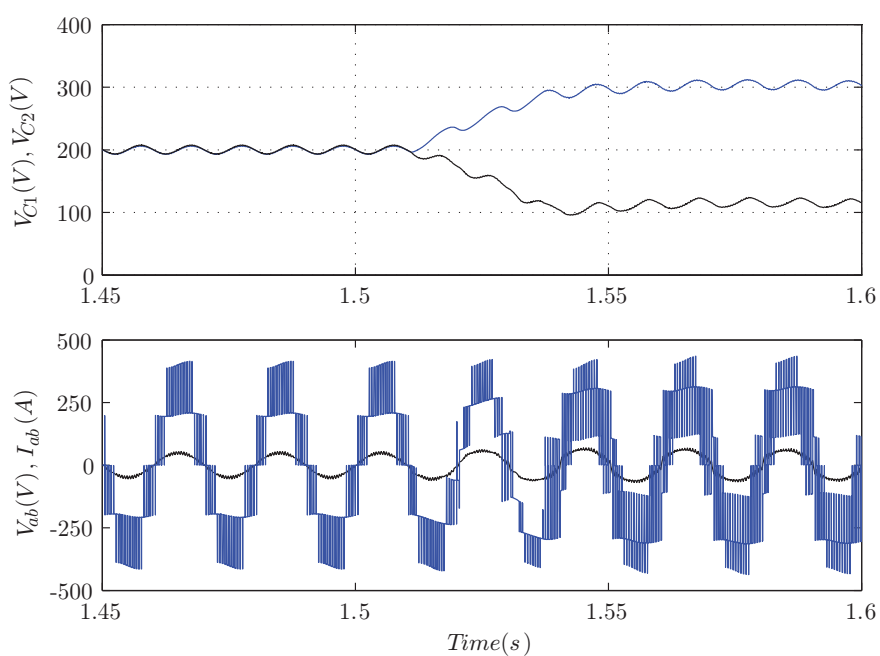

Fig. 10. Results of the 2DFFM technique changing the dc voltages references from $V_{C 1}^{*}=V_{C 2}^{*}=200 \mathrm{~V}$ to $V_{C 1}^{*}=300 \mathrm{~V}$ and $V_{C 2}^{*}=100 \mathrm{~V}$. From top to bottom: DC voltages $V_{C 1}$ and $V_{C 1}$, Phase voltage $V_{a b}$ and phase current $I_{a b}$.
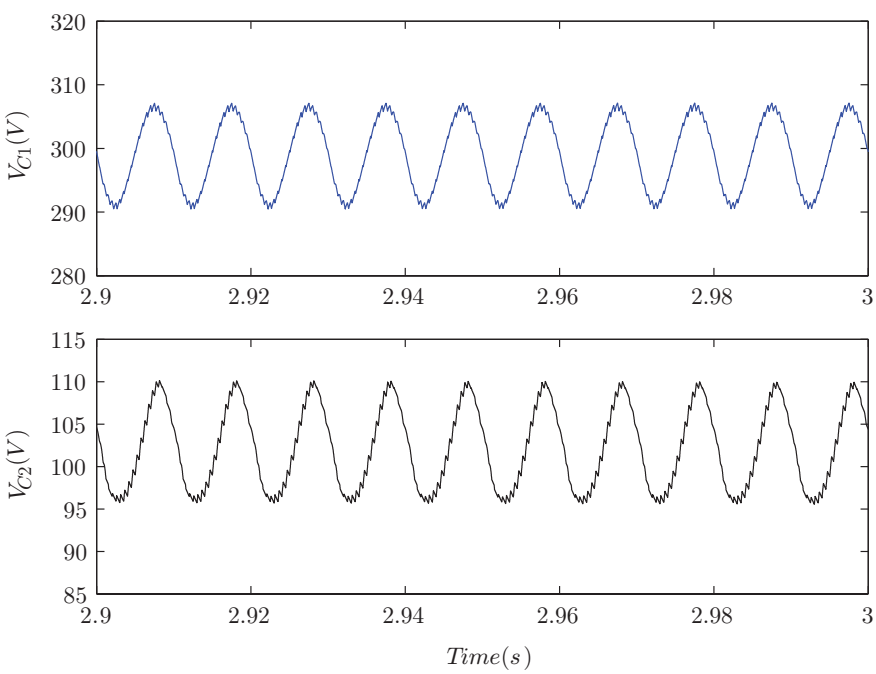

Fig. 11. Results of the 2DFFM technique achieving dc voltages balancing $\left(V_{C 1}^{*}=300 \mathrm{~V}\right.$ and $\left.V_{C 2}^{*}=100 \mathrm{~V}\right)$. Instantaneous dc voltage of the H-bridges $\left(V_{C 1}\right.$ and $\left.V_{C 2}\right)$.

chooses a specific switching sequence among all the possible ones achieving the desired objective. Using the 2DFFM technique with the dc voltage control, any dc voltage of the $\mathrm{H}$-bridges can be achieved without changing any additional control parameter. Some results are shown in order to validate the 2DFFM technique to achieve this goal.

\section{ACKNOWLEDGMENT}

The authors gratefully acknowledge financial support provided by the Spanish Education and Science Ministry under project TEC2007-61879.

\section{REFERENCES}

[1] D. Krug, S. Bernet, S. S. Fazel, K. Jalili and M. Malinowski, "Comparison of 2.3-kV Medium-Voltage Multilevel Converters for Industrial Medium-Voltage Drives," IEEE Trans. Ind. Electron., vol. 54, no. 6, pp. 2979-2992, Dec. 2007. 


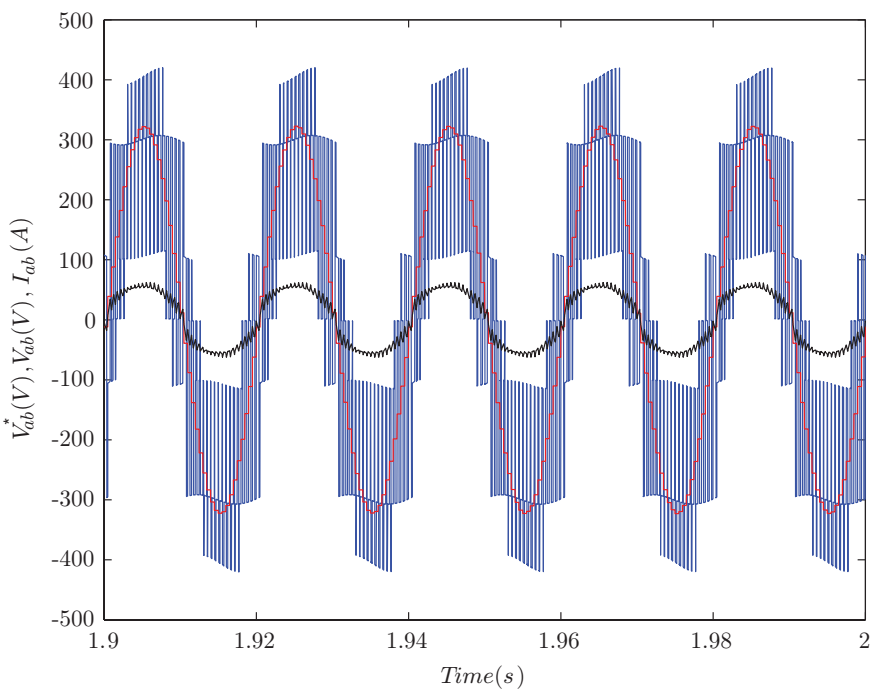

Fig. 12. Results of the 2DFFM technique achieving dc voltages balancing $\left(V_{C 1}^{*}=300 \mathrm{~V}\right.$ and $\left.V_{C 2}^{*}=100 \mathrm{~V}\right)$. Phase current $I_{a b}$, phase voltage $V_{a b}$ and phase voltage reference $V_{a b}^{*}$.
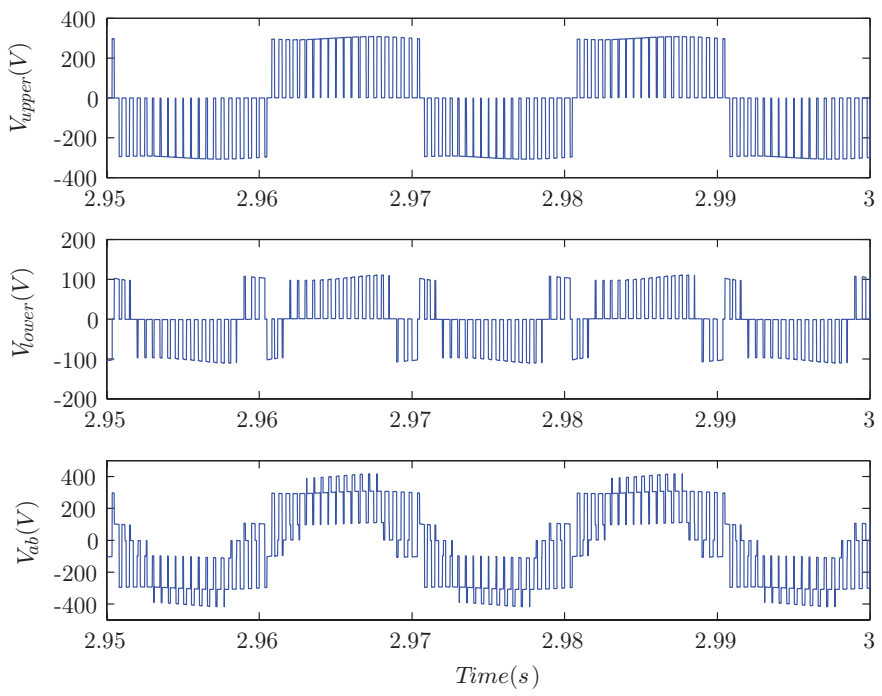

Fig. 13. Results of the 2DFFM technique achieving dc voltages balancing $\left(V_{C 1}^{*}=300 \mathrm{~V}\right.$ and $\left.V_{C 2}^{*}=100 \mathrm{~V}\right)$. Output voltage of upper and lower H-bridges (Vupper and $V_{\text {lower }}$ ) and phase voltage $V_{a b}$.

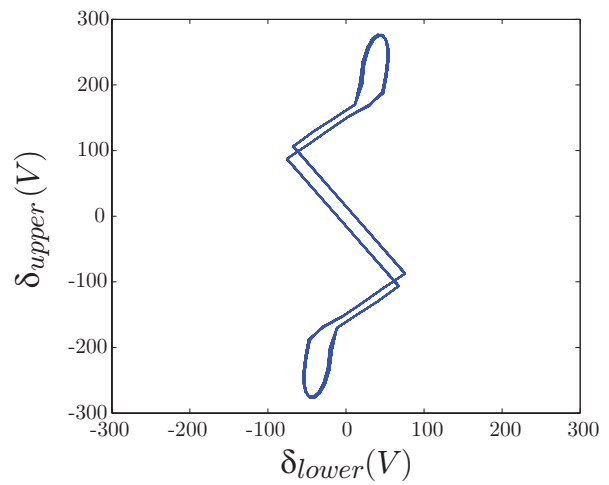

Fig. 14. Representation of the points used in the $2 \mathrm{D}$ control region in order to achieve dc voltages balancing $\left(V_{C 1}^{*}=300 \mathrm{~V}\right.$ and $\left.V_{C 2}^{*}=100 \mathrm{~V}\right)$.
[2] J. Rodriguez, S. Bernet, Bin Wu, J. O. Pontt and S. Kouro, "Multilevel Voltage-Source-Converter Topologies for Industrial Medium-Voltage Drives," IEEE Trans. Ind. Electron., vol. 54, no. 6, pp. 2930-2945, Dec. 2007.

[3] J. Rodriguez, L. G. Franquelo, S. Kouro, J. I. Leon, R. Portillo, M. M. Prats and M. A. Perez, "Multilevel Converters: An Enabling Technology for High-Power Applications," IEEE Proceedings, vol. 97, no. 11, pp. 1786-1817, Nov. 2009.

[4] L. G. Franquelo, J. Rodriguez, J. I. Leon, S. Kouro, R. Portillo and M. M. Prats, "The age of Multilevel Converters Arrives," IEEE Ind. Electron. Magazine, vol. 2, no. 2, pp. 28-39, June 2008.

[5] M. Malinowski, K. Gopakumar, J. Rodriquez and M. Perez, "A Survey on Cascaded Multilevel Inverters," in press.

[6] A. M. Massoud, S. J. Finney and B. W. Williams, "Systematic Analytical-Based Generalised Algorithm for Multilevel Space Vector Modulation with a Fixed Execution Time," IET Power Electron., vol. 1, no. 2, pp. 175-193, June 2008.

[7] D. G. Holmes and T. A. Lipo, "Pulse Width Modulation for Power Converters: Principles and Practice," IEEE Press Series on Power Engineering Publication, Wiley-IEEE Press, Oct. 2003.

[8] J. I. Leon, R. Portillo, S. Vazquez, J. J. Padilla, L. G. Franquelo and J. M. Carrasco, "Simple Unified Approach to Develop a TimeDomain Modulation Strategy for Single-Phase Multilevel Converters," IEEE Trans. Ind. Electron., vol. 55, no. 9, pp. 3239-3248, Sept. 2008.

[9] J. I. Leon, S. Vazquez, S. Kouro, L. G. Franquelo, J. M. Carrasco and J. Rodriguez, "Unidimensional Modulation Technique for Cascaded Multilevel Converters," IEEE Trans. Ind. Electron., vol. 56, no. 8, pp. 2981-2986, Aug. 2009

[10] V. Naumanen, J. Luukko, T. Itkonen, O. Pyrhonen and J. Pyrhonen, "Modulation technique for series-connected h-bridge multilevel converters with equal load sharing," IET Power Electron., vol. 2, no. 3, pp. 275-286, May 2009.

[11] M. Renge and M. Suryawanshi, "Three-Dimensional Space Vector Modulation to Reduce Common-Mode Voltage for Multilevel Inverter," IEEE Trans. Ind. Electron., in press.

[12] J. I. Leon, S. Vazquez, R. Portillo, L. G. Franquelo, S. Kouro and J. Rodriguez, "Two-dimensional Modulation Technique for Multilevel Cascaded H-bridge Converters," in IEEE International Conference on Industrial Technology (ICIT 2009), pp. 1-6, Melbourne (Australia), 1013 Feb. 2009.

[13] J. Pou, D. Boroyevich and R. Pindado, "New Feedforward Space-Vector PWM Method to Obtain Balanced AC Output Voltages in a Three-Level Neutral-Point-Clamped Converter," IEEE Trans. Ind. Electron., vol. 49, no. 5, pp. 1026-1034, Oct. 2002.

[14] S. Kouro, P. Lezana, M. Angulo and J. Rodriguez, "Multicarrier PWM With DC-Link Ripple Feedforward Compensation for Multilevel Inverters," IEEE Trans. Power Electron., vol. 23, no. 1, pp. 52-59, Jan. 2008.

[15] J. I. Leon, S. Vazquez, A. J. Watson, L. G. Franquelo, P. W. Wheeler and J. M. Carrasco, "Feed-forward Space Vector Modulation for SinglePhase Multilevel Cascade Converters with any DC voltage ratio," IEEE Trans. Ind. Electron., vol. 56, no. 2, pp. 315-325, Feb. 2009.

[16] J. I. Leon, S. Vazquez, R. Portillo, L. G. Franquelo, J. M. Carrasco, P. W. Wheeler and A. J. Watson, "Three-Dimensional Feed-Forward Space Vector Modulation Applied to Multilevel Diode-Clamped Converters," IEEE Trans. Ind. Electron., vol. 56, no. 1, pp. 101-109, Jan. 2009. 